\title{
REGULACIÓN DE LAS CLÁUSULAS ESCALONADAS EN COLOMBIA: ¿CONTRADICCIÓN DE PRINCIPIOS ENTRE EL DERECHO PROCESAL Y EL ARBITRAJE?"
}

\author{
REGULATION OF THE MULTI-TIER CLAUSES \\ IN COLOMBIA: CONTRADICTION OFPRINCIPLE \\ BETWEEN PROCEDURAL LAW AND ARBITRATION?
}

Nicolás Esteban Rosero Espinosa**

\begin{abstract}
Resumen
Pocos países han dedicado tanta atención a los convenios arbitrales escalonados, como lo ha hecho Colombia. Eso ha generado discusiones en múltiples escenarios, que se han consolidado en la regla que establece actualmente el artículo 13 del Código General del Proceso; norma que -a partir de una visión procesal del arbitraje- restringe los efectos jurídicos de tales acuerdos, por considerarlos obstáculos a la administración de justicia. Sin embargo, dicha restricción contradice
\end{abstract}

Recibido: 13 de marzo de 2017 - Aprobado: 5 de diciembre de 2017.

* Artículo inédito.

Fue preparado con base en la demanda de inconstitucionalidad contra el segundo inciso del artículo 13 del Código General del Proceso (Ley 1564 de 2016) que cursa actualmente ante la Corte Constitucional de Colombia.

Para citar el artículo: ROSERO ESPINOSA, Nicolás Esteban. Regulación de las cláusulas escalonadas en Colombia: Contradicción de principios entre el derecho procesal y el arbitraje. Revista del Instituto Colombiano de Derecho Procesal. No. 46 Julio - Diciembre. 2017, pp. 71-94.

** Abogado egresado de la Universidad Nacional de Colombia (Bogotá). Asociado del área de arbitraje en Bullard Falla Ezcurra+ (Lima, Perú). Profesor adjunto en la Pontificia Universidad Católica del Perú. Contacto: nrosero@bullardabogados.pe 
algunos de los principios originados en una visión flexible y consensual del arbitraje. Ello plantea dos cuestiones que se abordarán a lo largo de este escrito. Por un lado, identificar la tesis prevalente sobre la naturaleza jurídica del arbitraje en Colombia, y la conveniencia de mantener ese statu quo, y por otro, las implicaciones de carácter constitucional que plantea la restricción a las cláusulas escalonadas en el CGP.

Palabras clave: Cláusulas escalonadas, arbitraje, constitucionalidad, requisitos de procedibilidad, administración de justicia.

\begin{abstract}
Few countries have dedicated as much attention to multi-tier dispute resolution clauses as Colombia. The discussion has taken place in different scenarios, leading to the establishment of article 13 of the General Procedural Code. This norm -from a procedural point of view of arbitration- restrains the legal effects of such clauses, considering them obstacles to justice. Two questions then arise, each one of them will be addressed in this paper. The first one regards the identification of the legal nature of arbitration in Colombia, and the convenience of keeping the status quo. The second, the constitutional issues that come with the limitations to multi-tier dispute clauses contained in the general procedural code
\end{abstract}

Keywords: Multi-tier clauses, arbitration, constitutionality, procedural requirements, administration of justice.

\title{
Introducción
}

Una de las primeras cosas que aprendemos acerca del arbitraje, es que se trata de un mecanismo de solución de controversias alternativo a la justicia administrada por el Estado. Dicho carácter alternativo, ha llevado al arbitraje a nutrirse de características especiales que lo distinguen de la justicia tradicional, haciéndolo atractivo para sus usuarios. La flexibilidad y amplia libertad de las partes para diseñar el procedimiento son algunas de esas características.

Muchas legislaciones han incentivado esa independencia del arbitraje frente a la jurisdicción nacional, mediante regímenes legales que son abiertos a la aplicación de estándares internacionales ${ }^{1}$. Donde la flexibilidad del procedimiento es aún mayor, incluso en controversias con alcance eminentemente nacional. A ese tipo de legislaciones se les conoce como "monistas".

1 Perú es un gran ejemplo, mediante el Decreto Legislativo $\mathrm{N}^{\circ} 1071$ que norma el arbitraje. 
En contraposición, los países que abogan por un régimen "dualista" hacen una marcada diferencia entre el arbitraje nacional e internacional, estableciendo reglas especiales para cada uno. Colombia pertenece a este grupo de países, a través de la Ley 1563 de 2012.

Dejando a un lado las consideraciones acerca de la conveniencia de un modelo legal sobre el otro, dicha división plantea efectos prácticos. Uno de ellos, en el caso de las legislaciones dualistas, es la reducción del carácter alternativo del arbitraje nacional respecto de los procedimientos y formas de la justicia estatal. A tal punto que las normas de procedimiento general suelen tener un papel protagónico en la administración del procedimiento arbitral nacional ${ }^{2}$.

Prueba de lo anterior es la restricción para pactar cláusulas escalonadas ${ }^{3}$ que hace el artículo 13 del Código General del Proceso (CGP) en Colombia. A pesar que dichos pactos son de naturaleza arbitral, como un desarrollo de la liberad contractual de las partes para diseñar el procedimiento; el legislador colombiano, basado en consideraciones de naturaleza jurisdiccional/procesal, ha sancionado este tipo de pactos con la ineficiencia jurídica por considerarlos un obstáculo para la administración de justicia.

Lo anterior genera una pugna a dos niveles. En el primero, se enfrenta una visión procesal del arbitraje frente a una que propugna por la liberalización del procedimiento arbitral - con base en la voluntad de las partes. Ello, a su vez, asciende a un segundo nivel, que paradójicamente se origina por la "nacionalización" del arbitraje. Ello lleva a que los principios arbitrales se irradien por la Constitución Política nacional, generando una suerte de "constitucionalización del arbitraje".

$\mathrm{Al}$ aterrizar la restricción a las cláusulas escalonadas en este segundo nivel, se genera una colisión de principios constitucionales que depende en gran medida de la concepción sobre la naturaleza jurídica del arbitraje que se posea.

El objetivo del presente escrito será aprovechar las discusiones que ofrece el artículo 13 del CGP en los dos niveles comentados, a fin de establecer el impacto de dicha norma en la relación entre el derecho procesal y el arbitraje. El interrogante que trascenderá los siguientes párrafos, será acerca del grado de autonomía -o dependencia- que el derecho arbitral debería tener respecto del proceso general en Colombia.

La estructura del escrito estará divida de la siguiente manera. Se realizará (1) un acercamiento al alcance de las cláusulas escalonadas, y (2) sus antecedentes

Por ejemplo, quinto inciso del artículo 20 de la Ley 1563 de 2012.

También suelen ser denominadas como multi-tier clauses, escalation clauses o multistep alternative dispute resolution clauses. 
en Colombia. Con base en ello (3) se plantearán algunas reflexiones sobre la tesis predominante del arbitraje en Colombia, y (4) el impacto constitucional de la regulación actual en la materia.

\section{Alcance de los convenios arbitrales escalonados}

La denominación cláusulas o convenios "escalonadas" es bastante ilustrativa a fin de entender su alcance. Imaginemos que surge una controversia entre dos -o más partes que han pactado un acuerdo arbitral escalonado, estas, a fin de solucionarla, estarán obligadas a subir una serie de escalones ${ }^{4}$. El primer escalón regularmente se compone por mecanismos de solución amistosa de $\operatorname{controversias}^{5}$ (o, "MASC" en adelante), como la negociación, conciliación, o amigable composición. En la medida que las partes avanzan en sus acercamientos sin lograr un acuerdo, continuarán en su escalada hasta llegar al último peldaño, el cual suele estar compuesto por una vía litigiosa, como el arbitraje -o la justicia estatal ${ }^{6}$.

Un elemento común a este tipo de cláusulas, además de los escalones previos, es la existencia de plazos entre las distintas etapas, a fin de evitar que las negociaciones se prologuen indefinidamente ${ }^{7}$. De suerte tal que al cumplimiento del plazo cualquiera de las partes puede activar el arbitraje. La duración de dichas etapas suele ser corta, entre uno o dos meses aproximadamente, como por ejemplo la cláusula escalonada modelo de la Cámara de Comercio Internacional (que establece 45 días) ${ }^{8}$.

Mediante estos pactos se fomentan "negociaciones exitosas a fin de que ni el litigio ni el arbitraje sean necesarios". Bajo ciertas condiciones, "estas cláusulas

$4 \quad$ Por regla general estas cláusulas sólo prevén dos escalones, pero nada obsta para que las partes pacten más.

5 BLACKABY, Nigel, PARTASIDES, Constantine, et al. "Redfern and Hunter on International Arbitration". Kluwer Law International and Oxford University Press. 2015, par. 2.88 .

6 También pienso que aplica a justicia estatal.

7 El pacto de estos plazos es recomendado por la International Bar Association. "Directrices de la IBA para la Redacción de Cláusulas de Arbitraje Internacional" en: http:// www.oas.org/es/sla/ddi/docs/arbitraje_buenas_directrices_IBA.pdf

8 Cámara de Comercio Internacional. "La CCI y la solución de controversias: Una amplia experiencia, un acervo de conocimientos" en: http://www.iccmex.mx/uploads/uploads/ arbitraje2015/ICC_Dispute_Resolution_SPANISH.pdf.

$9 \quad$ ESTADOS UNIDOS. Corte de Apelaciones de Estados Unidos para el Séptimo Circuito. Welborn Clinic v Medquist Inc. 2002. 301 3d 634, 638. 
tienen el potencial de promover la resolución temprana de conflictos con mínimas asperezas facilitando las discusiones iniciales en contextos menos adversarios"10. El éxito y eficiencia de estas disposiciones depende principalmente del carácter vinculante que las partes les imprimen, en virtud de su autonomía privada de la voluntad.

Existen diversas razones que pueden motivar la suscripción de este tipo de cláusulas ${ }^{11}$. Una de ellas es que permiten armonizar los intereses de las partes, causando que las divergencias desaparezcan desde la raíz. A diferencia de lo que ocurre en el arbitraje o en la justicia estatal, los métodos no-litigiosos que contemplan los acuerdos arbitrales escalonados permiten un acuerdo consensuado. De hecho, la posibilidad de lograr una solución "win-win" sólo existe en los métodos de autocomposición. Lo cual incentiva a mantener en firme la relación negocial de las partes.

De igual manera, las cláusulas escalonadas plantean una ecuación costo-beneficio favorable para las partes, en tanto generan "un acercamiento entre las partes para que solucionen el conflicto con menores costos y en menor tiempo, y que sólo acudan al arbitraje en caso de que sea completamente necesario"12.

No existe consenso a nivel global sobre los efectos del acuerdo arbitral escalonado. Sin embargo, la tendencia mayoritaria de los tribunales judiciales se ha encaminado a aceptar sus efectos vinculantes ${ }^{13}$. No obstante, el caso colombiano -yendo contra la corriente- ha planteado restringirlas por disposición legal. Para comprender cómo el legislador colombiano llegó a tal conclusión es necesario dar un vistazo de los antecedentes.

10 FILE, J. "United States: Multistep Dispute Resolution Clauses" en IBA Legal Practice Division, Mediation Committee Newsletter. London. 2007, p. 36.

11 CAIVANO, Roque. "Las cláusulas 'escalonadas' de resolución de conflictos (negociación, mediación o conciliación previas al arbitraje)" en Soto Coaguila, Carlos Alberto. Tratado de derecho arbitral. Tomo I. Bogotá: Pontificia Universidad Javeriana, Grupo Editorial Ibáñez, Instituto Peruano de Arbitraje. 2011, pp. 70-71.

12 BERNAL GUTIÉRREZ, Rafael, PUYO POSADA, Esteban, GONZÁLEZ ARRIETA, Felipe, et al. "Las Cláusulas Escalonadas o Multinivel: Su Aproximación en Colombia". Arbitraje: Revista de Arbitraje Comercial y de Inversiones. Vol. 5. 2012. CIAMEN, pp. $169-203$.

13 TORTEROLA, Ignacio. "Cláusulas escalonadas en el arbitraje de inversión" en Soto Coaguila, Carlos Alberto. Tratado de derecho arbitral. Tomo I. Bogotá: Pontificia Universidad Javeriana, Grupo Editorial Ibáñez, Instituto Peruano de Arbitraje. 2011, pp. 288-89; IBA Litigation Committee. "Multi-Tiered dispute resolution clauses". 2015, p. 78; FILE, J. Op. cit. 


\section{Antecedentes de la regulación sobre las cláusulas escalonadas en Colombia}

Al igual que sucede con la solución de controversias al aplicar una cláusula escalonada, la discusión en Colombia sobre este tipo de pactos ha debido escalar diversos peldaños. Los primeros se han dado en la (i) esfera arbitral, pasando por (ii) el poder judicial, hasta llegar a la cúspide en (iii) el poder legislativo.

En el primer peldaño (i), es paradigmático el caso Telefónica Móviles Colombia S.A. vs. Empresa de Telecomunicaciones de Bogotá S.A. E.S.P ${ }^{14}$. En este caso la parte demandante inició el arbitraje sin haber agotado los escalones previos del convenio arbitral. A pesar de ello, el Tribunal Arbitral se declaró competente, y resolvió la controversia, argumentando que la cláusula escalonada no impedía la iniciación unilateral del procedimiento arbitral

El tenor de esta decisión llevó la discusión a un segundo peldaño (ii), en tanto ETB presentó recurso de anulación contra el laudo, y -en paralelo- acción de tutela contra el Tribunal Arbitral alegando que sus derechos al debido proceso y al acceso a la administración de justicia habían sido vulnerados. Antes que se decidiera la anulación, la Corte Constitucional declaró la nulidad del laudo arbitral, esbozando -entre otras cosas- que el Tribunal Arbitral había incurrido en una vía de hecho por defecto orgánico porque "no se agotaron las etapas previstas con anterioridad a su conformación"15.

A criterio de la Corte Constitucional: “(...) la falta de conformación del Comité Mixto de Interconexión, así como de las demás etapas previstas de manera previa a la conformación de dicho Tribunal, inhabilitaba la constitución de este y lo hacía incompetente para decidir sobre el conflicto propuesto por telefónica. Al respecto, es necesario reiterar que el fundamento constitucional y legal de las formas de arreglo directo previstas por las partes de un contrato para la solución de las controversias que surjan entre ellas, se encuentra en su voluntad de someter sus diferencias por fuera del ámbito de la justicia estatal y, en esa medida, no puede entenderse que esta decisión no sea tenida en cuenta a la hora de finiquitar el conflicto y verificar si se agotaron los medios no judiciales previstos para ello"16.

Una tesis similar fue defendida por el Tribunal Superior del Distrito Judicial de Bogotá, en el caso Bancolombia S.A. contra los Gilinsky, donde declaró nulo

14 COLOMBIA. Tribunal de arbitramento Telefónica Móviles Colombia S.A. vs. Empresa de Telecomunicaciones de Bogotá S.A. Laudo. 07 de noviembre de 2007. Árbitros: Juan Carlos Henao, Jorge Enrique Ibáñez Najar y Anne Marie Mürrle Rojas.

15 COLOMBIA. Corte Constitucional. Sentencia T-058/09. 2 de febrero de 2009. MP. Jaime Araujo Rentería. Expediente T-1960031.

16

Ibid. 
el laudo arguyendo la validez y fuerza vinculante de las cláusulas escalonadas, por ser una representación de la voluntad de las partes, que genera efectos procesales ${ }^{17}$. Para el Tribunal, este tipo de cláusulas quita del conocimiento de la jurisdicción arbitral el asunto, y hace que su solución se confié a otros mecanismos establecidos por las partes.

Contra dicho laudo se presentó acción de tutela ante la Corte Suprema de Justicia. En primer lugar, la Sala de Casación civil suspendió los efectos del fallo ${ }^{18}$. Y posteriormente, dicha decisión fue impugnada, y revocada por la Sala de Casación laboral ${ }^{19}$, por considerar que existía otro medio de defensa disponible y no se configuraba un perjuicio irremediable. A pesar que la controversia estuvo relacionada con las cláusulas escalonadas, la Corte Suprema no entró al fondo del asunto, sino que se restringió al análisis de la tutela ${ }^{20}$.

No obstante, quien sí se ha pronunciado sobre las cláusulas escalonadas ha sido el Consejo de Estado, el cual ha sostenido una tesis contraria a la defendida por la Corte Constitucional y el Tribunal Superior de Bogotá; creando así un "choque de trenes".

Para el Consejo de Estado este tipo de pactos vulnera el acceso a la administración de justicia, debido a que "no constituyen presupuestos de procedibilidad para acceder a la justicia arbitral y por lo mismo su omisión no entraña consecuencia alguna en el ámbito procesal ni configura nulidad alguna en cuanto a la validez de la constitución del tribunal de arbitramento (...) tales estipulaciones no pueden generar efectos procesales para los árbitros, ante quienes una de las partes acude en la búsqueda de la solución de una controversia, por cuanto la autonomía privada encuentra sus precisos límites en la Constitución y en la ley que garantizan el ejercicio y goce de dicho derecho"21.

17 COLOMBIA. Tribunal Superior del Distrito Judicial de Bogotá. Sentencia de 26 de febrero de 2008. MP. Germán Valenzuela Valbuena. Expediente 0887; ALJURE SALAME, Antonio. "Comentario a la sentencia de anulación del laudo arbitral Bancolombia v. Gilinski”. Bogotá: Revista Internacional de Arbitraje. 2008.

18 COLOMBIA. Corte Suprema de Justicia, Sala Civil. Sentencia del 28 de marzo de 2008. Magistrado Ponente: Edgardo Villamil Portilla Expediente 00384.

19 COLOMBIA. Corte Suprema de Justicia, Sala Laboral. Sentencia de mayo 13 de 2008. Acta 23. MP. Luis Javier Osorio López. Radicado 20951.

20 BERNAL GUTIÉRREZ, Rafael, PUYO POSADA, Esteban, GONZÁLEZ ARRIETA, Felipe, et al. Op, cit., p. 194.

21 COLOMBIA. Consejo de Estado. Sala de lo Contencioso Administrativo. Sentencia del 10 de junio de 2009. Consejera Ponente doctora Ruth Stella Correa Palacio. Expediente número 1100103260002008003200. De igual manera, en Sentencia del 29 de agosto de 2007. Expediente No. 110010326000070001100. 
El contraste entre estas visiones, influenció el (iii) tercer peldaño compuesto por el Congreso de la Republica, el cual debatió en tres oportunidades la suerte de las cláusulas escalonadas. La primera de ellas sucedió en los debates del Estatuto Nacional e Internacional de Arbitraje, en cuyo momento se había propuesto una disposición con el siguiente tenor: “(...) Son válidos las estipulaciones de las partes que establezcan condiciones o el agotamiento de requisitos de procedibilidad para acceder al arbitraje. Sin embargo, la inobservancia de tales condiciones o requisitos no constituirá un incumplimiento del contrato, ni afectará la competencia del Tribunal Arbitral para conocer de la controversia"22.

Mediante la citada norma, el legislador se inclinaba por una posición intermedia entre las vertientes jurisprudenciales existentes ${ }^{23}$. Sin embargo, planteaba un alcance poco afortunado, pues a pesar del reconocimiento de validez del acuerdo escalonado, sus efectos vinculantes eran prácticamente inexistentes. Sin perjuicio de ello, un punto positivo por resaltar de esta propuesta, es que se planeaba regular las cláusulas escalonadas en la ley arbitral, lo cual resulta más plausible considerando la especialidad de la materia. Mas al final, esta propuesta no se convirtió en ley.

Así, la cuestión se trasladó a los debates del Código General del Proceso, dando como resultado el artículo $13^{\circ}$ cuyo texto establece: “(...) Las estipulaciones de las partes que establezcan el agotamiento de requisitos de procedibilidad para acceder a cualquier operador de justicia no son de obligatoria observancia. El acceso a la justicia sin haberse agotado dichos requisitos convencionales, no constituirá incumplimiento del negocio jurídico en donde ellas se hubiesen establecido, ni impedirá al operador de justicia tramitar la correspondiente demanda. Las estipulaciones de las partes que contradigan lo dispuesto en este artículo se tendrán por no escritas".

Con esta norma, el legislador optó por la posición del Consejo de Estado, y estableció una proscripción -considerada por algunos como "tajante"24 - de las cláusulas escalonadas. Ello bajo el argumento que este tipo de pactos tienen

22 COLOMBiA. Congreso de la Republica. Gaceta del Congreso 946 de 2011. Informe de ponencia segundo debate proyecto de Ley 18 de 2011 Senado por medio de la cual se expide el Estatuto de Arbitraje Nacional e Internacional y se dictan otras disposiciones.

23 Ibid.

24 ROBledo DEL CASTILlO, Pablo Felipe. "El Estatuto de Arbitraje y el Código General del Proceso en Comité Colombiano de Arbitraje" en Estatuto arbitral colombiano: Análisis y aplicación de la Ley 1563 de 2012. Bogotá: Legis Editores, Comité Colombiano de Arbitraje. 2013, p. 333. 
"propósito o como efecto impedir o restringir el derecho al libre acceso a la administración de justicia"25.

En la actualidad cursa contra esta disposición una demanda de inconstitucionalidad por varios de los motivos que se desarrollaran en este escrito ${ }^{26}$. Por su parte, el legislador en un tercer peldaño, propuso el Proyecto de Ley 096 de 2017, que eliminaba por completo el segundo inciso del artículo 13 del CGP ${ }^{27}$. Sin embargo, fue retirado antes de convertirse en ley. Sin perjuicio de ello, estos dos ejemplos dan fe de la vigencia de la discusión.

\section{Del debate sobre la naturaleza del arbitraje a la regulación de las cláusulas escalonadas en Colombia}

Las discusiones que se han presentado en torno a las cláusulas arbitrales escalonadas rememoran una clásica disputa sobre la naturaleza jurídica del arbitraje, donde dos extremos se han enfrentado. Por una parte, quienes defienden el origen contractual del arbitraje, conforme lo cual es el acuerdo de las partes el que dota de esencia a este mecanismo ${ }^{28}$. Mientras que, por otro lado, están aquellos que sostienen que el arbitraje es esencialmente un acto jurisdiccional, asimilable a la función de un juez ${ }^{29}$.

25 COLOMBIA. Congreso de la República. Gaceta del Congreso 261 del 23 de mayo de 2012. Informe de Ponencia Segundo Debate Proyecto de Ley 159 de 2011 Senado y 196 de 2011 Cámara por la cual se expide el Código General del Proceso y se dictan otras disposiciones. Disponible en: http://www.imprenta.gov.co/gacetap/gaceta.indice?v num=261\&v_anog=2012 (visitado el 10 de junio de 2016).

26 COLOMBIA. Corte Constitucional. Auto admisorio de la demanda de inconstitucionalidad contra el artículo 13 (parcial) de la Ley 1564 de 2012. 13 de febrero 2017. Magistrado Ponente: Alberto Rojas Ríos. Expediente D-11922.

27 La propuesta decía: “ARTÍCULO 13. Las normas procesales son de orden público y, por consiguiente, de obligatorio cumplimiento, y en ningún caso podrán ser derogadas, modificadas o sustituidas por los funcionarios o particulares, salvo autorización expresa de la ley.

Las estipulaciones de las partes que establezcan el agotamiento de requisitos de procedibilidad para acceder a cualquier operador de justicia que tengan como finalidad obstruir el libre acceso a la administración de justicia serán absolutamente nulas". Sin embargo, desaprovechaba la oportunidad para regular de manera más completa las cláusulas escalonadas en Colombia, Lo cual, en todo caso, considero que es más apropiado realizar en el Estatuto Arbitral.

28 STEINGRUBER, Andrea M. "Consent in International Arbitration". Reino Unido: Oxford University Press. 2012, p. 55.

$29 \quad$ Ibíd., p. 54. 
Si bien, a la actualidad la discusión se ha zanjado mediante una posición ecléctica $^{30}$, el arbitraje constantemente se tambalea sobre la frontera que divide ambos extremos. En muchos casos, la respuesta a algunos interrogantes requiere inclinarse en una u otra posición. Siendo este es el caso de las cláusulas escalonadas.

Esto se ejemplifica a la perfección tomando los criterios adoptados por las altas cortes. La Corte Constitucional, y el Tribunal Superior de Bogotá, soportan una tendencia contractualista, en tanto es la voluntad de las partes la que da origen y esencial al arbitraje, por ende, los particulares poseen plena libertad para requerir el agotamiento de etapas previas sin que por ello se vulnere el acceso a la administración de justicia ${ }^{31}$.

Por su parte, el Consejo de Estado pone énfasis en el lado jurisdiccional del arbitraje. En esa lógica, interpreta los escalones previos establecidos en las cláusulas escalonadas como "requisitos de procedibilidad", los cuales únicamente podrían ser establecidos por el legislador, mas no por particulares.

El que esta última posición se privilegiara en la legislación colombiana es muestra del marcado sentido jurisdiccional del arbitraje en el país, máxime cuando es la normativa procesal general la que se encarga del tema, y no el estatuto de arbitraje como estaba inicialmente previsto. De esta manera, se desconoce que el arbitraje es ante todo una "criatura del contrato", y en cuanto tal, las partes lo moldean a la conveniencia de ambas.

No obstante, ello se presenta principalmente en arbitraje nacional, pues en materia internacional tiende a reconocerse mayor libertad para las partes en el procedimiento. Cabría preguntarse si dicho tratamiento diferenciado tiene razón hoy en día, o si por el contrario resulta favorable a los constructos arbitrales poner énfasis en la consensualidad del arbitraje, incluso en materias nacionales.

Sin perjuicio de ello, aun en arbitraje nacional dicha libertad ha sido reconocida constitucionalmente, y defendida en algunas ocasiones. Por tal motivo, en los siguientes párrafos se analizará la incidencia de la restricción a las cláusulas escalonadas en la perspectiva constitucional del arbitraje.

\footnotetext{
$30 \quad$ Ibid.

31 COLOMBIA. Corte Constitucional. Sentencia T-058/09. Op, cit.
} 
Nicolás Esteban Rosero Espinosa

\section{Impacto constitucional de la restricción a las cláusulas escalonadas en Colombia}

\subsection{Aplicabilidad del art. 13 del CGP al arbitraje, en tanto mecanismo transitorio de administración de Justicia}

Como se señaló en un primer momento, la división entre arbitraje nacional e internacional genera que el arbitraje nacional tienda a impregnarse de las características del procedimiento judicial. Así, el artículo 116 de la Constitución Política dispone que los árbitros son particulares "investidos transitoriamente de la función de administrar justicia”. Esta claridad es importante a los efectos del presente escrito, pues la restricción de las cláusulas escalonadas (art. 13 CGP) se dirige a defender el acceso a todo "operador de justicia", por lo que el arbitraje se entendería incluido en su alcance.

El Consejo de Estado resume muy bien el asunto en los siguientes términos: "No debe olvidarse que, por mandato constitucional (inciso $4^{\circ}$ del artículo 116 Superior), los árbitros son transitoriamente verdaderos jueces y están habilitados para proferir fallos, en los términos que determine la ley. Si la jurisdicción recae en el Estado y esa faceta del poder público está concebida para sustituir la voluntad de las partes, estas últimas no pueden por acuerdo negocial modificar las reglas procesales y establecer condiciones previas como condición sine qua non para poder ocurrir ante la Justicia, sea esta institucional o arbitral"32.

Los árbitros son asimilables a los jueces, ya que mediante un procedimiento preestablecido analizan hechos y pruebas, a efectos de extraer una consecuencia definitoria que quedará plasmada de un laudo arbitral, el "que formal y materialmente es revestido de las características de verdadera sentencia, pues se trata de un acto de declaración de certeza del derecho, que produce efectos de cosa juzgada"33.

\subsection{Principios constitucionales del arbitraje vulnerados por la restricción de las cláusulas escalonadas}

La limitación establecida por el segundo inciso del artículo 13 del CGP merma la materialización de diversos principios de la Constitución Nacional. En concreto afecta: 1) la autonomía privada de la voluntad; 2) el alcance del margen de configuración de los procedimientos judiciales y arbitrales que posee el legislador;

32 COLOMBIA. Consejo de Estado. Sala de lo Contencioso Administrativo. Sentencia del 10 de junio de 2009. Op. cit.

33 COLOMBIA. Corte Constitucional. Sentencia C-242 de 1997. 20 de mayo de 1997. Magistrado Ponente: Hernando Herrera Vergara. Expediente D-1501. 
3) las funciones y finalidades de la administración de justicia; y 4) el principio de buena fe contractual y su presunción a favor de los contratantes.

\subsubsection{Vulneración de la autonomía de la voluntad privada}

La norma del CGP en cuestión tiene como efectos: 1) prohibir tajantemente ${ }^{34}$ a los particulares pactar cláusulas escalonadas; 2) limitar la posibilidad de pactar el contenido de sus cláusulas de solución de conflictos; y 3) eliminar los efectos jurídicos de este tipo de pactos.

Esta prohibición limita la autonomía de la voluntad privada de las partes y su libertad contractual, que de acuerdo con la Corte Constitucional se fundamentan en los principios constitucionales de libertad (Art. 13), libre desarrollo de la personalidad (Art. 16) y libertad económica (Art. 333) ${ }^{35}$. Como la misma Corte ha señalado, el núcleo fundamental de la autonomía de la voluntad privada lo constituye el poder de las personas para disponer "con efecto vinculante de los intereses y derechos de los que son titulares y por ende crear derechos y obligaciones" ${ }^{\prime 36}$. Esto se comprueba por medio de la libertad para celebrar contratos con la simple manifestación de consentimiento, la libre determinación del contenido de las obligaciones y derechos correlativos, y la creación de relaciones obligatorias inter-partes ${ }^{37}$.

Esta serie de libertades, a su vez incluyen la facultad de las partes para decidir la manera más apropiada para resolver las controversias que puedan surgir con motivo de sus negocios. En tal sentido, "[s]i algún significado ha de dársele al principio de autonomía de la voluntad, que estructura todo el régimen de contratación nacional (pública y privada), éste tiene que ver con la posibilidad de que sean las propios sujetos de la relación jurídica, quienes decidan el destino de su vínculo y obviamente, los procedimientos y autoridades que habrán de resolver los eventuales desacuerdos; de esta forma se garantiza, no sólo el recto y libre ejercicio de la voluntad individual, sino el adecuado acceso a la administración de justicia"38.

34 ROBLEDO DEL CASTILLO, Pablo Felipe. Op. cit., p. 333.

35 COLOMBIA. Corte Constitucional. Sentencia C-1194/08. 3 de diciembre de 2008. MP. Rodrigo Escobar Gil. Expediente D-7379. De igual manera en COLOMBIA. Corte Constitucional. Sentencia C-993/06. 29 de noviembre de 2006. MP. Jaime Araujo Rentería. Expediente D-6349.

36 Ibíd. COLOMBIA. Corte Constitucional. Sentencia C-341 de 2006. 3 de mayo de 2006. MP. Jaime Araujo Rentería. Expediente D-6020.

37 COLOMBIA. Corte Constitucional. Sentencia C-934 de 2013. MP. Nilson Pinilla Pinilla. Expediente D-9661.

38 COLOMBIA. Corte Constitucional. Sentencia C-060 de 2001. 24 de enero de 2001. Magistrado Ponente: Carlos Gaviria Díaz. Expediente D-3089. 
El pacto de las cláusulas escalonadas es justamente un desarrollo de esa libertad, en tanto es una manera de establecer procedimientos y competencias para resolver los conflictos entre las partes. Ello se consigue fomentado la aplicación de MASC como etapas previas a la solución judicial/arbitral de una controversia. Es decir, las partes no auto-restringen su acceso a la justicia, ni la posibilidad de solucionar sus controversias, solo establecen mecanismos previos para acceder a la justicia, dejando al juicio arbitral o judicial como ultima ratio.

Lo anterior demuestra que la norma cuestionada, desconoce el principio de libre autonomía de la voluntad. En palabras del profesor Roque Caivano, desconocer este tipo de cláusulas implica "lisa y llanamente, negar la fuerza vinculante de un compromiso contractual asumido, en violación a los principios fundamentales del derecho de los contratos. Elementales razones de buena fe y respeto a lo pactado llevan a concluir que, si las partes convinieron que debían intentar una solución acordada a través de negociaciones directas o asistidas, una de ellas no puede luego evadir esa primera instancia" ${ }^{39}$.

\subsubsection{El legislador excede la libertad de configuración de los procedimientos judiciales/arbitrales}

El legislador tiene amplia libertad para diseñar y configurar los procedimientos que se originen en procesos, actuaciones y acciones de derecho sustancial ${ }^{40}$, como es el caso del arbitraje. Esta función es encomendada por el constituyente primario al poder legislativo mediante el artículo 150 de la Constitución Política ${ }^{41}$, y tiene como finalidad desarrollar el derecho fundamental al debido proceso (artículo 29 C.P.), y del acceso efectivo a la administración de justicia (artículo 229 C.P.).

Sin embargo, la amplitud de esta facultad no implica que el legislador puede crear leyes procedimentales de manera absolutamente discrecional o arbitraria ${ }^{42}$. Esta función se encuentra limitada por los valores y principios constitucionales ${ }^{43}$.

39 CAIVANO, Roque. Op. cit, p. 74.

40 COLOMBIA. Corte Constitucional. Sentencia C-555 de 2001. 31 de mayo de 2001. Magistrado Ponente: Marco Gerardo Monroy Cabra. Expediente D-3243; COLOMBIA. Corte Constitucional. Sentencia C-927/00. 12 de julio de 2000. MP. Alfredo Beltrán Sierra. Expediente D-2807.

41 COLOMBIA. Corte Constitucional. Sentencia C- 203 de 2011. 24 de marzo de 2011. MP. Juan Carlos Henao Pérez. Expediente D-8237.

42 Ibid. Esto se ha reiterado en COLOMBIA. Corte Constitucional. Sentencia C- 227 de 2009. 30 de marzo de 2009. MP. Luis Ernesto Vargas Silva. Expediente D-7402.

43 COLOMBIA. Corte Constitucional. Sentencia C-1104 de 2001. 24 de octubre de 2001. MP. Clara Inés Vargas Hernández. Expediente D-3488. 
En ese sentido la jurisprudencia constitucional ha decantado varios criterios para garantizar que los límites descritos sean respetados por el legislador. A saber ${ }^{44}$ :

\section{a. Atender a los principios y fines del Estado}

La realización del régimen democrático, la participación de los ciudadanos en la toma de decisiones que los afectan y la convivencia pacífica, son principios básicos del Estado Social de Derecho que se desprenden de los artículos 1 y 2 de la Constitución ${ }^{45}$. Los mismos resultan perjudicados por la restricción de las cláusulas escalonadas, en tanto se desincentiva el uso de MASC como escalones previos a los procedimientos judiciales o arbitrales.

En efecto, los principios y fines comentados son desarrollados mediante los MASC, en tanto: 1) permiten espacios de intervención de la comunidad para evitar la conflictivización de la sociedad ${ }^{46}$. De forma que cuando las partes resuelven sus controversias en estos ámbitos, del poder judicial puede enfocarse en las desavenencias que tienen mayor trascendencia social, dotando de legitimidad a la administración de justicia ${ }^{47}$; de otro lado, 2) facilitan la participación de todos en las decisiones que los afectan y aseguran la convivencia pacífica entre los ciudadanos ${ }^{48}$.

El efecto que genera la prohibición de las cláusulas escalonadas, es totalmente adverso pues fomenta que las partes litiguen, en lugar de solucionar sus conflictos amistosamente. Ello se traduce en arrebatarles la solución de la controversia a las partes, para entregársela a un tercero (juez o árbitro), incluso cuando dichas partes de antemano habían acordado procurar primero una solución consensuada.

44 COLOMBIA. Corte Constitucional. Sentencia C- 203 de 2011. Op. cit. También en COLOMBIA. Corte Constitucional. Sentencia C- 227 de 2009. Op. cit.

45 COLOMBIA. Corte Constitucional. Sentencia C-163 de 1999. 17 de marzo de 1999. MP. Alejandro Martínez Caballero. Expediente D-2169.

46 COLOMBIA. Corte Constitucional. Sentencia C-893 de 2001. 22 de agosto de 2001. MP. Clara Inés Vargas Hernández. Expediente D-3399.

47 Ibid.

48 COLOMBIA. Corte Constitucional. Sentencia C-222 de 2013. 17 de abril de 2013. MP. María Victoria Calle Correa. Expediente D-9317; COLOMBIA. Corte Constitucional. Sentencia C-098/01. 31 de enero de 2001. MP. Martha Victoria Sáchica Méndez. Expediente D-3179: “(...) el arbitramento como la conciliación o la amigable composición, han de entenderse como institutos a los que el Constituyente les reconoció una función fundamental dentro la administración de justicia (...) lo que permite no sólo la descongestión del aparato de justicia sino la participación activa de los particulares en la definición de sus conflictos".

84 Revista del Instituto Colombiano de Derecho Procesal • No. 46 


\section{b. Velar por la vigencia de los derechos fundamentales de los ciudadanos en materia procesal}

En segundo lugar, la Corte Constitucional ha planteado la necesidad de velar por los derechos fundamentales con importancia procesal. En ese marco, la autonomía de la voluntad privada se encuentra incluida, pues a partir de ella las partes pueden escoger la vía para solucionar sus controversias, y en caso de elegir al arbitraje, diseñar las reglas de procedimiento que las partes y los árbitros seguirán. Por este motivo, el legislador debe permitir un margen amplio a dicha autonomía en materia arbitral ${ }^{49}$, de manera que, si las partes deciden establecer etapas previas al arbitraje, tal decisión debería ser avalada. Lo contrario supone un exceso de las funciones del legislador, tal como ha sucedido con el artículo 13 del CGP.

\section{c. Obrar conforme a los principios de razonabilidad y proporcionalidad en la definición de las formas}

Para determinar la razonabilidad y proporcionalidad de la norma, una herramienta útil es el test de proporcionalidad ${ }^{50}$, el cual se compone de tres conceptos: adecuación; necesidad; y proporcionalidad en sentido estricto. Aplicado esto a la restricción de las cláusulas escalonadas, se podría aceptar que existe adecuación de la norma del CGP, puesto que el fin perseguido por el legislador es legítimo, el cual describe Pablo Felipe Robledo -miembro de la comisión redactora del CGP: "[s]e trata de una disposición ambiciosa y garantista del sagrado derecho constitucional de acceso a la justicia, en cuanto prohíbe las denominadas "cláusulas escalonadas"

No obstante, los medios escogidos para proteger el fin perseguido son inadecuados, debido a que -como lo ha reconocido la guardiana de la constitución- las cláusulas escalonadas no representan una afectación al derecho al acceso a la administración de justicia ${ }^{52}$, luego su prohibición en nada contribuye a la protección de este derecho. Además, el resultado de la norma es adverso al propósito buscado, ya que desestimula la utilización de MASC, los cuales desarrollan una visión más amplia de justicia, que las tradicionales vías litigiosas.

49 COLOMBIA. Corte Constitucional. Sentencia SU-174 de 2007. 14 de marzo de 2007. MP. Manuel José Cepeda Espinosa. Expediente T-980611.

50 COLOMBIA. Corte Constitucional. Sentencia C-022 de 1996. 23 de enero de 1996. MP. Carlos Gaviria Díaz. Expediente D-1008. La Corte Constitucional también ha referido al principio de proporcionalidad como herramienta hermenéutica en las Sentencias T-015 de 1994, C-309 de 1997. C-475 de 1997, C-392 de 2002.

$51 \quad$ Pablo Felipe Robledo. Op. cit.

52 COLOMBIA. Corte Constitucional. Sentencia T-058/09. Op. cit. 
Esto impacta en el segundo concepto, pues torna innecesaria la restricción. El concepto de necesidad exige que los medios utilizados, sacrifiquen en la menor medida posible los principios constitucionales afectados para proteger el fin legítimo buscado. Al respecto, vemos como la norma en cuestión soslaya casi en su totalidad la libre autonomía privada de la voluntad, sin que se demuestre cómo ello beneficia al acceso a la administración de justicia. De hecho, como se verá en el siguiente punto, la restricción del CGP parece defender una idea de justicia limitada únicamente al litigio judicial y arbitral, restándole importancia a las vías alternativas.

Esto lleva al último concepto, denominado proporcionalidad en sentido estricto entre medios y fines. El cual busca evitar que los principios que dotan de fundamento al fin pretendido, no sacrifiquen otros principios constitucionalmente más importantes ${ }^{53}$. Como señala Robert Alexy, se busca evitar la colisión de derechos, y ponderación entre ellos ${ }^{54}$.

En lo que a este aspecto concierne, el grado de vulneración de la libre autonomía de la voluntad es intenso en tanto la norma prohíbe casi totalmente la autonomía de las partes para pactar cláusulas escalonadas, castigando el pacto en contrario con la ineficacia de pleno derecho. Por su parte, el acceso a la administración de justicia solo se puede considerar levemente vulnerado, pues como lo ha advertido esta Corporación, las cláusulas escalonadas no violentan este derecho $\mathrm{o}^{55}$. Tendría que pensarse en circunstancias demasiado particulares e individualizadas para que este tipo de pactos limiten al menos someramente la administración de justicia.

Lo anteriormente visto enseña que la vulneración a la libre autonomía de la voluntad es sustancialmente superior a la administración de justicia, lo cual genera que la norma acusada sea irrazonable y desproporcionada respecto a los fines que pretende proteger.

\section{d. Permitir la realización material de los derechos y del principio de la primacía del derecho sustancial sobre las formas}

El objetivo de la primacía del derecho sustancial sobre las formas es "la efectividad de los derechos y su eficacia material, y que además propendan por la optimización de los medios de defensa de las personas"56. Sin embargo, la norma del CGP cierra todas las vías alternas para la solución de conflictos, dejando

\footnotetext{
53 Ibid.

54 ALEXY, Robert. “Teoría de los derechos fundamentales”. Centro de Estudios Políticos y Constitucionales. Madrid. 1997, p. 90.

55 COLOMBIA. Corte Constitucional. Sentencia T-058/09. Op. cit.

56 COLOMBIA. Corte Constitucional. Sentencia C-227 de 2009. Op. cit.
} 
a las partes encaminadas únicamente por el procedimiento judicial y arbitral. Los cuales, como se ha indicado, suelen ser menos eficientes en comparación con los MASC ${ }^{57}$. De esta forma, al conducir a las partes por mecanismos más complejos y poco agiles, se obstaculiza la realización de la justicia de manera óptima y eficiente.

El incumplimiento del legislador a todos los puntos señalados lleva a concluir que ha excedido sus funciones y límites para diseñar el procedimiento arbitral, a través de la restricción a los acuerdos arbitrales escalonados.

\subsubsection{Afectación a las funciones y finalidades de la administración de justicia}

Como se ha insistido a lo largo de este escrito, la norma acusada vulnera los postulados de la administración de justicia toda vez que propone una visión restringida de la misma, de acuerdo con la cual son solo los jueces, árbitros o en general "cualquier operador de justicia" quienes la administran. Esto deja de lado los MASC donde la noción formal de operador de justicia no existe, mas sirven para la solucionar conflictos bajo una idea de justicia alternativa.

La Corte Constitucional ha reconocido un sentido amplio de la administración de justicia, según la cual "el derecho a acceder a la justicia exige en todas y cada una de las etapas del proceso que la actividad de justicia esté orientada a facilitar la solución pacífica de los conflictos y asegurar de manera efectiva el goce de los derechos. Y esta regla se aplica tanto a la justicia formal, como a los mecanismos alternativos de solución pacífica de conflictos" ${ }^{\prime 2}$.

En ese sentido, los MASC son "otra forma de hacer efectivo el derecho de acceso a la administración de justicia, y (...) son un buen mecanismo para lograr la descongestión judicial" ${ }^{29}$. En tanto justicia formal y MASC comparten la misma finalidad, su tratamiento por parte del legislador debería ser igual de relevante en ambos casos. Pero particular importancia debería ser puesta en la

57 GIRALDO SERNA, Juliana María. "Los MASC, aliados del crecimiento empresarial". Ámbito Jurídico. Bogotá. 13 de octubre del 2016 en: https://www.ambitojuridico.com/ BancoConocimiento/Mercantil-Propiedad-Intelectual-y-Arbitraje/los-masc-aliados-del-crecimiento-empresarial.cshtm: "[S]egún un reciente estudio de los tres centros más importantes del país [Bogotá, Cali y Medellín], el 70 \% de los casos tramitados con este mecanismo resulta siendo un acuerdo, y es resuelto en menos de 11 días, reafirmando a la conciliación como una figura útil y rápida que restablece relaciones y mejora la productividad de las empresas, pues les permite continuar de manera dinámica con su negocio sin estancarse en el conflicto".

58 COLOMBIA. Corte Constitucional. Sentencia C-222 de 2013. Op. cit.

59 Ibid. COLOMBIA. Corte Constitucional. Sentencia C-330 de 2012. 9 de mayo de 2012. MP. Humberto Antonio Sierra Porto. Expediente D-8677. 
voluntad de las partes respecto de las MASC, en tanto es la puerta de entrada para activarlos ${ }^{60}$.

Sin el deseo de las partes inmersas en la controversia, estos mecanismos no tendrían ninguna eficacia. Es la libertad de las partes para resolver por sus propios medios sus controversias la manera como se exterioriza esta forma de justicia material. Sin embargo, la restricción del CGP cierra este camino, y lleva necesariamente a las partes a accionar ante los operadores de la justicia formal.

El debate al respecto puede reducirse en la siguiente forma. La Corte Constitucional mediante una interpretación auténtica ${ }^{61}$ de la Constitución Política ha defendido que pactar cláusulas escalonadas no constituye una vulneración al acceso a la administración de justicia ${ }^{62}$. Mientras que el legislador colombiano motiva la norma del CGP señalando que estos pactos suelen ser "en ocasiones sumamente costosos en términos de tiempo y dinero"63. No obstante, esta última posición ignora que tanto la justicia estatal como el arbitraje poseen costos mayúsculos en comparación con los MASC.

La razón es lógica. Los procesos judiciales ${ }^{64}$ y arbitrales ${ }^{65}$ poseen un entramado complejo donde interactúan una serie de sujetos y factores, tales como: presentación de demanda, contestación, audiencias, peritajes, inspecciones judiciales, honorarios de abogados, honorarios de árbitros, entre otros. Todo esto implica gastos para las partes y un procedimiento extenso hasta la emisión de la sentencia o laudo que ponga fin al asunto.

60 COLOMBIA. Corte Constitucional. Sentencia C-893 de 2001. Op. cit.

61 COLOMBIA. Corte Constitucional. Sentencia T-175 de 1997. 8 de abril de 1997. MP. José Gregorio Hernández Galindo. Expedientes acumulados T-114880 y otros.

62 COLOMBIA. Corte Constitucional. Sentencia T-058/09. Op, cit: "Si se tiene que las partes decidieron resolver sus controversias por fuera de la administración de justicia del Estado, es claro que dicha decisión no puede configurar una violación del derecho fundamental al acceso a la administración de justicia de quien la toma".

63 COLOMBIA. Congreso de la República. Gaceta del Congreso 261 del 23 de mayo de 2012. Op., cit.

64 Corporación Excelencia en la Justicia. "Tablero de indicadores generales de justicia en Colombia" en: https://docs.google.com/spreadsheets/d/1fOTae9wdvvfaexh7f1yUtBXuu kmSbn_1iN16nUHtwnw/pubhtml (visitado el 31 de agosto de 2016). En el año de 2011 los tiempos procesales promedio según especialidad eran de 625,2 días en materia civil, 1.136,5 días en laboral y 1.143,0 días en administrativo.

65 En una encuesta realizada a diferentes expertos en arbitraje se les pregunto ¿cuál son las tres peores características del arbitraje internacional? Dentro de las diez principales características escogidas, la primera fue costos en un 68\% y la cuarta el tiempo en un 36\%. Queen Mary University of London \& White \& Case, '(2015 International Arbitration survey: Improvements and Innovations in International Arbitration' (QMUL, 2015) <http://www. arbitration.qmul.ac.uk/docs/164761.pdf> (revisado el 23 de Agosto de 2016). 
De todo lo expuesto se puede concluir que la prohibición establecida por el legislador para pactar clausulas escalonadas, desconoce la estructura de la administración de justicia en Colombia y representa un detrimento al derecho para acceder a la misma.

\subsubsection{Restricción de la buena fe contractual y su presunción en favor de los contratantes}

La norma del CGP también desconoce el principio general de la buena fe establecido en el artículo 83 de la Constitución Política, por dos razones. En primer lugar, la Corte Constitucional ha sostenido que la buena fe tiene gran influencia en las actuaciones entre particulares ${ }^{66}$. Según el principio de buena fe contractual, las partes vinculadas por un acto jurídico actúan bajo los parámetros de la recta disposición de la razón, dirigida al cumplimiento fiel de las obligaciones derivadas del acto. Se trata de reconocer que una parte que ha asumido obligaciones, procederá con honestidad, lealtad y moralidad a fin de cumplirlas.

Interpretada a la luz del Código Civil (Artículo 1603), la buena fe constituye un criterio regulador de conducta, $y$, ante todo, un principio habilitador para que las partes puedan suscribir libremente negocios jurídicos, siempre que se amparen bajo sus postulados. Esto se basa en la expectativa de que lo pactado será vinculante y cumplido recíprocamente. Si el ordenamiento jurídico impide ese cumplimiento, mediante el despojo de los efectos de lo pactado -como sucede con las cláusulas escalonadas, tal expectativa se verá defraudada. Lo ideal, conforme a la buena fe, es que "la parte que invoca la obligatoriedad y el cumplimiento de los escalones iniciales de una cláusula multinivel tiene derecho a que se decrete tal obligatoriedad y a que se cumpla con dichos escalones, así el resultado vaya a ser fútil o no se vaya a solucionar efectivamente el conflicto" ${ }^{67}$.

Esta vulneración de la buena fe además se vislumbra en una segunda forma, pues contrario a lo exigido por la Constitución, se construye una presunción de mala fe en contra de las partes que suscriben las cláusulas escalonadas. En efecto, el legislador fundamenta la norma acusada sosteniendo que las cláusulas escalonadas "tienen como propósito o como efecto impedir o restringir el derecho al libre acceso a la administración de justicia (...)"68.

66 COLOMBIA. Corte Constitucional. Sentencia C-865 de 2004. 7 de septiembre de 2004. MP. Rodrigo Escobar Gil. Expediente D-5057.

67 LÓPEZ ANTON, Félix. "Ejecución en España de laudos arbitrales extranjeros (La aplicación del Convenio de Nueva York)”. Diario La Ley. 1985, p. 1190.

68 COLOMBIA. Congreso de la República. Gaceta del Congreso 261 del 23 de mayo de 2012. Op. cit. 
Esta asunción parte de premisas erradas, pues supone que la intención de las partes al pactar estas cláusulas es sortear la justicia estatal o arbitral, de manera dolosa. Por el contrario, debería primar una interpretación desde la buena fe según la cual, las partes al pactar "escalones" previos al arbitraje tienen la intención de resolver la controversia de manera amistosa, económica y celera antes de acudir ante jueces y árbitros.

\section{Conclusiones}

La pugna por las cláusulas escalonadas en Colombia ha atravesado un importante debate sobre la naturaleza jurídica del arbitraje, que paulatinamente se ha impregnado por consideraciones de naturaleza iusfundamental. En estos niveles dos conclusiones se han alcanzado a lo largo del presente ensayo:

1. La tesis prevalente en Colombia sobre el arbitraje nacional es principalmente de orden procesal, anteponiéndose a la visión contractual.

2. Por otro lado, el segundo inciso del artículo 13 del CGP vulnera diversos derechos y principios del arbitraje a nivel constitucional.

Lo anterior lleva a reflexionar acerca de si la senda que el derecho arbitral y el derecho procesal han recorrido juntos, debe empezar a individualizarse. Queda claro que la influencia procesal es importante en el arbitraje -principalmente el nacional. Sin embargo, éste también se ha influencia características que lo hacen alternativo al proceso general. En razón de ello, las normas arbitrales deberían guardar mayor independencia.

Esto por supuesto, no supone convertir al arbitraje en una figura eminentemente contractual, pues, así como su carácter consensual es innegable, también lo es su alto contenido procesal. Lo que se trata es que compaginar ambos extremos en aras de lograr mayor especialidad frente a las otras formas de solución de controversias.

Ahora bien, en lo que a la regulación de las cláusulas escalonadas como tal concierne, ninguno de los dos extremos -contractualista y jurisdiccional- brinda una solución adecuada a la problemática planteada. Las cláusulas escalonadas no pueden ser analizadas desde un solo punto de vista, puesto que en cada caso existen circunstancias que inclinan la balanza hacia una u otra decisión, por lo siempre corresponderá hacer una evaluación individualizada.

En esta lógica, el análisis contractual-jurisdiccional debería ser reemplazado por uno de jurisdicción-admisibilidad. Entendiendo por jurisdicción al poder del árbitro/juez para conocer del proceso, y admisibilidad, a si existen vicios que afectan -pero no eliminan- la jurisdicción del Tribunal ${ }^{69}$.

69 Al respecto en el caso CIADI. Waste Management, Inc. v. United Mexican States. Caso No. ARB(AF)/98/2. Opinión Disidente del árbitro Keith Highet, 8 mayo 2000, párr. 58, 
En ese sentido las posiciones adoptadas por el Consejo de Estado, la Corte Constitucional y el Tribunal Superior de Bogotá ven el problema solamente como uno de jurisdicción, pues lo que importa es si el Tribunal Arbitral puede o no conocer del procedimiento. Para el Consejo de Estado es así, puesto que la existencia de una cláusula escalonada no afecta de ninguna manera la jurisdicción arbitral. Y también sucede con la Corte Constitucional y el Tribunal Superior, porque perciben los efectos procesales de las cláusulas escalonadas en el sentido de arrebatarle a los árbitros el conocimiento de la causa, para someterla a los MASC.

Ignoran de esta manera que pueda tratarse de una situación de admisibilidad, donde perfectamente el Tribunal pueda constituirse y conocer del caso, y hecho esto, decidir qué efectos tiene la cláusula escalonada. Pudiendo así, generarse hipótesis como la suspensión del procedimiento arbitral mientras se intentan solucionar amistosamente las desavenencias. A través de esta visión se podrían sortear problemas como los términos de caducidad, prescripción o la adopción de medidas cautelares, que, ante la existencia de una cláusula escalonada tienen la potencialidad de perjudicar los derechos de alguna de las partes.

Es posible también que el Tribunal con base en el principio del competence-competence declare que no goza de jurisdicción, y, en consecuencia, exhorte a las partes a agotar las etapas previas antes del procedimiento arbitral. En este contexto, resulta más garantista hacia las libertades de las partes que caso por caso, el Tribunal Arbitral o los jueces quienes decidan la suerte de la cláusula escalonada. Lo que es contrario a una prohibición legal absoluta.

La labor del legislador será importante en tanto establezca criterios objetivos que puedan utilizar los operadores jurídicos al momento de decidir estas cuestiones. Para ello podría valerse de experiencias internacionales, como las directrices de la $\mathrm{IBA}^{70}$.o decisiones de tribunales extranjeros.

No obstante, la norma como está planteada en la actualidad debería ser objeto de modificación por el legislador, considerando lo antes señalado, o una propuesta que compagine las libertades de las partes con la naturaleza jurisdiccional del arbitraje. Hasta que ello no suceda, el segundo inciso del artículo 13 del CGP permanecerá contrario a principios arbitrales y constitucionales.

se estableció que: “[j]urisdicción es el poder del tribunal para conocer una causa; admisibilidad es si el caso, en sí, está viciado, si es apropiado que el tribunal lo conozca. Si no existe título de jurisdicción, el tribunal no puede actuar" 
Regulación de las cláusulas escalonadas en Colombia

\section{Referencias bibliográficas}

\section{Libros}

ALEXY, Robert. "Teoría de los derechos fundamentales". Centro de Estudios Políticos y Constitucionales. Madrid. 1997.

BLACKABY, Nigel, PARTASIDES, Constantine, et al. "Redfern and Hunter on International Arbitration”. Kluwer Law International and Oxford University Press. 2015.

STEINGRUBER, Andrea M. "Consent in International Arbitration". Reino Unido: Oxford University Press. 2012.

\section{Leyes y jurisprudencia}

CIADI. Waste Management, Inc. v. United Mexican States. Caso No. ARB(AF)/98/2. Opinión Disidente del árbitro Keith Highet, 8 mayo 2000.

COLOMBIA. Congreso de la República. Ley 1563 de 2012 (julio 12).

COLOMBIA. Congreso de la República. Gaceta del Congreso 946 de 2011. Informe de ponencia segundo debate proyecto de Ley 18 de 2011 Senado por medio de la cual se expide el Estatuto de Arbitraje Nacional e Internacional y se dictan otras disposiciones.

COLOMBIA. Congreso de la República. Gaceta del Congreso 261 del 23 de mayo de 2012. Informe de Ponencia Segundo Debate Proyecto de Ley 159 de 2011 Senado y 196 de 2011 Cámara por la cual se expide el Código General del Proceso y se dictan otras disposiciones.

COLOMBIA. Consejo de Estado. Sala de lo Contencioso Administrativo. Sentencia del 10 de junio de 2009. CP. Ruth Stella Correa Palacio. Expediente número 1100103260002008003200 .

COLOMBIA. Corte Constitucional. Auto admisorio de la demanda de inconstitucionalidad contra el artículo 13 (parcial) de la Ley 1564 de 2012. 13 de febrero 2017. MP. Alberto Rojas Ríos. Expediente D-11922.

COLOMBIA. Corte Constitucional. Sentencia C-022 de 1996. 23 de enero de 1996. MP. Carlos Gaviria Díaz. Expediente D-1008.

COLOMBIA. Corte Constitucional. Sentencia T-175 de 1997. 8 de abril de 1997. MP. José Gregorio Hernández Galindo. Expedientes acumulados T-114880 y otros.

COLOMBIA. Corte Constitucional. Sentencia C-242 de 1997. 20 de mayo de 1997. MP. Hernando Herrera Vergara. Expediente D-1501.

COLOMBIA. Corte Constitucional. Sentencia C-163 de 1999. 17 de marzo de 1999. MP. Alejandro Martínez Caballero. Expediente D-2169.

COLOMBIA. Corte Constitucional. Sentencia C-927/00. 12 de julio de 2000. MP. Alfredo Beltrán Sierra. Expediente D-2807.

COLOMBIA. Corte Constitucional. Sentencia C-060 de 2001. 24 de enero de 2001. MP. Carlos Gaviria Díaz. Expediente D-3089.

COLOMBIA. Corte Constitucional. Sentencia C-098/01. 31 de enero de 2001. MP. Martha Victoria Sáchica Méndez. Expediente D-3179.

COLOMBIA. Corte Constitucional. Sentencia C-555 de 2001. 31 de mayo de 2001. MP. Marco Gerardo Monroy Cabra. Expediente D-3243. 
COLOMBIA. Corte Constitucional. Sentencia C-893 de 2001. 22 de agosto de 2001. MP. Clara Inés Vargas Hernández. Expediente D-3399.

COLOMBIA. Corte Constitucional. Sentencia C-1104 de 2001. 24 de octubre de 2001. MP. Clara Inés Vargas Hernández. Expediente D-3488.

COLOMBIA. Corte Constitucional. Sentencia C-865 de 2004. 7 de septiembre de 2004. MP. Rodrigo Escobar Gil. Expediente D-5057.

COLOMBIA. Corte Constitucional. Sentencia C-341 de 2006. 3 de mayo de 2006. MP. Jaime Araujo Rentería. Expediente D-6020.

COLOMBIA. Corte Constitucional. Sentencia C-993/2006. 29 de noviembre de 2006. MP. Jaime Araujo Rentería. Expediente D-6349.

COLOMBIA. Corte Constitucional. Sentencia SU-174 de 2007. 14 de marzo de 2007. MP. Manuel José Cepeda Espinosa. Expediente T-980611.

COLOMBIA. Corte Suprema de Justicia, Sala Civil. Sentencia del 28 de marzo de 2008. MP. Edgardo Villamil Portilla Expediente 00384.

COLOMBIA. Corte Suprema de Justicia, Sala Laboral. Sentencia de mayo 13 de 2008. Acta 23. MP. Luis Javier Osorio López. Radicado 20951.

COLOMBIA. Corte Constitucional. Sentencia C-1194/2008. 3 de diciembre de 2008. MP. Rodrigo Escobar Gil. Expediente D-7379.

COLOMBIA. Corte Constitucional. Sentencia T-058/2009. 2 de febrero de 2009. MP. Jaime Araujo Rentería. Expediente T-1960031.

COLOMBIA. Corte Constitucional. Sentencia C- 227 de 2009. 30 de marzo de 2009. MP. Luis Ernesto Vargas Silva. Expediente D-7402.

COLOMBIA. Corte Constitucional. Sentencia C- 203 de 2011. 24 de marzo de 2011. MP. Juan Carlos Henao Pérez. Expediente D-8237.

COLOMBIA. Corte Constitucional. Sentencia C-330 de 2012. 9 de mayo de 2012. MP. Humberto Antonio Sierra Porto. Expediente D-8677.

COLOMBIA. Corte Constitucional. Sentencia C-222 de 2013. 17 de abril de 2013. MP. María Victoria Calle Correa. Expediente D-9317.

COLOMBIA. Corte Constitucional. Sentencia C-934 de 2013. 11 de diciembre de 2013. MP. Nilson Pinilla Pinilla. Expediente D-9661.

COLOMBIA. Tribunal de arbitramento Telefónica Móviles Colombia S.A. vs. Empresa de Telecomunicaciones de Bogotá S.A. Laudo. 07 de noviembre de 2007. Árbitros: Juan Carlos Henao, Jorge Enrique Ibáñez Najar y Anne Marie Mürrle Rojas.

COLOMBIA. Tribunal Superior del Distrito Judicial de Bogotá. Sentencia de 26 de febrero de 2008. MP. Germán Valenzuela Valbuena. Expediente 0887.

ESTADOS UNIDOS. Corte de Apelaciones de Estados Unidos para el Séptimo Circuito. Welborn Clinic v Medquist Inc. 2002. 301 3d 634, 638.

\section{Publicaciones científicas}

ALJURE SALAME, Antonio. "Comentario a la sentencia de anulación del laudo arbitral Bancolombia v. Gilinski”. Bogotá: Revista Internacional de Arbitraje. 2008.

BERNAL GUTIÉRREZ, Rafael, PUYO POSADA, Esteban, GONZÁLEZ ARRIETA, Felipe, et al. "Las Cláusulas Escalonadas o Multinivel: Su Aproximación en Colombia". Arbitraje: Revista de Arbitraje Comercial y de Inversiones. Vol. 5. 2012. CIAMEN. 
CAIVANO, Roque. "Las cláusulas 'escalonadas' de resolución de conflictos (negociación, mediación o conciliación previas al arbitraje)” en Soto Coaguila, Carlos Alberto. Tratado de derecho arbitral. Tomo I. Bogotá: Pontificia Universidad Javeriana, Grupo Editorial Ibáñez, Instituto Peruano de Arbitraje. 2011.

CÁMARA DE COMERCIO INTERNACIONAL. La CCI y la solución de controversias: Una amplia experiencia, un acervo de conocimientos en:http://www.iccmex.mx/ uploads/uploads/arbitraje2015/ICC_Dispute_Resolution_SPANISH.pdf

CORPORACIÓN EXCELENCIA EN LA JUSTICIA. "Tablero de indicadores generales de justicia en Colombia” en: https://docs.google.com/spreadsheets/d/1fOTae9wdvvfaexh7f1yUtBXuukmSbn_1iN16nUHtwnw/pubhtml

FILE, J. "United States: Multistep Dispute Resolution Clauses" en IBA Legal Practice Division, Mediation Committee Newsletter. London. 2007.

GIRALDO SERNA, Juliana María. "Los MASC, aliados del crecimiento empresarial”. Ámbito Jurídico. Bogotá. 13 de octubre del 2016.

IBA Litigation Committee. "Multi-Tiered dispute resolution clauses". 2015 en http:// www.ibanet.org/LPD/Dispute_Resolution_Section/Litigation/multitiereddisputeresolution.aspx

INTERNATIONAL BAR ASSOCIATION. "Directrices de la IBA para la Redacción de Cláusulas de Arbitraje Internacional” en: http://www.oas.org/es/sla/ddi/docs/arbi traje_buenas_directrices_IBA.pdf

LÓPEZ ANTON, Félix. "Ejecución en España de laudos arbitrales extranjeros (La aplicación del Convenio de Nueva York)”. Diario La Ley. 1985.

PAULSSON, Jan. "Jurisdiction and admissibility" en Global reflections on International Law: Commerce and dispute resolution. ICCP. 2005.

QUEEN MARY UNIVERSITY y WHITE \& CASE. “2015 International Arbitration survey: Improvements and Innovations in International Arbitration”. QMUL. 2015.

ROBLEDO DEL CASTILlO, Pablo Felipe. "El Estatuto de Arbitraje y el Código General del Proceso en Comité Colombiano de Arbitraje" en Estatuto arbitral colombiano: Análisis y aplicación de la Ley 1563 de 2012. Bogotá: Legis Editores, Comité Colombiano de Arbitraje. 2013.

TORTEROLA, Ignacio. "Cláusulas escalonadas en el arbitraje de inversión" en Soto Coaguila, Carlos Alberto. Tratado de derecho arbitral. Tomo I. Bogotá: Pontificia Universidad Javeriana, Grupo Editorial Ibáñez, Instituto Peruano de Arbitraje. 2011. 